\title{
Active Citizenship and Neighborhood Governance; North-Western Literature and Global South Realities
}

\author{
Aya Elwageeh ${ }^{1,2, *}$, Maarten van Ham ${ }^{1,3}$, Reinout Kleinhans ${ }^{1}$ \\ ${ }^{1}$ Department of Urbanism, Faculty of Architecture and the Built Environment, Delft University of Technology, The Netherlands \\ ${ }^{2}$ Department of Urban Design and Planning, Faculty of Engineering, Ain Shams University, Egypt \\ ${ }^{3}$ School of Geography and Sustainable Development, University of St Andrews, UK
}

Received November 5, 2019; Revised February 2, 2020; Accepted February 7, 2020

Copyright $\mathrm{C} 2020$ by authors, all rights reserved. Authors agree that this article remains permanently open access under the terms of the Creative Commons Attribution License 4.0 International License

\begin{abstract}
Active citizenship related to neighborhood governance is dependent on the political and governance structures of its context, and is therefore different in the Global North and the Global South. Local active citizenship is often presented from a North-western perspective, with its own active culture of engagement. In contrast, it is often shaped by an unfamiliar culture of engagement in parts of the Global South. This difference questions the applicability of the leading literature in understanding Global South realities. The paper aims to answer this question by reviewing the literature on local activism in both contexts. This review elaborates on the commonality of "context"; while highlighting the variation of "right-based vs. need-based" and "state-citizen collaboration vs. selective state-citizen collaboration" as central dimensions of local activism in both worlds. In result, we conclude that the leading literature on active citizenship in the context of neighborhood governance is limited in its explanation of local activism found in parts of the Global South. Finally, this review paper contributes to inform future empirical research on how to better understand neighborhood activism in contexts of the Global South. In this regard, the deduced commonalities and variations offer a starting point to scholars and offer dimensions which could be investigated to improve our understanding of active resident groups, and eventually contribute to more effective local activism.
\end{abstract}

Keywords Active Citizenship, Neighborhood Governance, Global South, North-Western, Culture of Engagement

\section{Introduction}

There is increasing academic and policy interest in "active citizenship" in the context of "neighborhood governance". Most of the local active citizenship literature in international peer-reviewed academic journals is written from a North European or a North American perspective. This is partly due to the dominance of English language in academic journals [1,2]. But importantly, it is also because these concepts are part of the broader argument about the leading role of the North-western perspective and experiences in urban studies theorization. Thus, this paper argues that a Non-Western and Global South perspective is needed to develop a body of knowledge capable of understanding diverse cities [3-7]. Current debates on the appropriate representation of "Global South" focus on the lack of diversity and inclusivity in urban studies [8], and argue the need for a new starting point from ex-centric locations [4]. This broader argument needs to move forward from abstract notions to answering Mabin's question [2, p. 27] about "what city/society relationships in the hyper-diverse 'south' elude ideas formed in the 'west' or 'north'?". With this question, this paper focuses on the commons and variations between the North-western dominant perspective and the residents' practices in parts of the global South concerning the specific concept of active citizenship in neighborhood governance.

The "Global North" literature on citizens' active participation in planning emphasizes that its rise is related to the socio-political and economic trajectories of NorthWestern countries [9]. These trajectories are driven by neoliberal practices leading the North-Western states to take on a role as responsive enabler in fostering "willing, able and equipped" citizens [10, p. 492]. Meanwhile, the Global South -which is very diverse by itself- is different from the Global North in terms of culture, history and institutions [11]. Consequently, distinctive forms of activism are manifested in neighborhood governance there. A relatively small body of literature addresses active residents' groups in the formal neighborhoods of the Global South. This is 
especially the case for the unregistered active residents' groups functioning inside formal neighborhoods as observed in Global South cities such as Johannesburg [12] and Cairo. The actions of these groups can be related to the concept of "informal tactics" [13], which means that they exist outside the official channels to practice activism. In this paper, we argue that these practices of activism are not only different from the North-Western practices in terms of their manifestation, ideology and state-citizen dynamics. But also different from the literature on Global South that majorly links the informal practices of local activism with informal, marginalized and struggling areas.

This paper aims to achieve a better understanding of the applicability of Global North perspectives and experiences to local active citizenship in Global South realities. Asserting the importance of context in urban studies [see $3,14,15]$, the paper will start by reviewing the context and manifestation of residents' activism in neighborhood governance in parts of the Global South as well as in the North-Western literature. Next, the characteristics of active citizens' groups in examples from Cairo and Johannesburg cities will be confronted with those in the leading NorthWestern literature. In result, the paper deduces the commonalities and differences in dimensions of activism in neighborhood governance in the two contexts. According to these dimensions, the applicability of Global North perspective in the Global South realities will be discussed. As a final note, the active groups will be referred to as active residents' groups to reduce the politically loaded connotations with "citizens" term.

\section{Active Citizenship and Neighborhood Governance in the Context of the Global South}

This section will focus on highlighting active citizenship practices in neighborhood governance in the Global South. It will conclude with a description of the distinctive characteristics of local activism in parts of the Global South. But first, the paper will highlight the socio-political context that has shaped this local activism.

\subsection{The Global South Context}

It is important to note that the socio-political trajectories are unique between countries [5], however many countries in the Global South context share aspects of their history, current problems and future challenges. The history of post-colonial authoritarian regimes and inherited traditional planning policies and processes from the Northwest, are pinpointed as shared histories $[1,2,16]$. Yiftachel [1] and Watson [16] highlighted that currently adopted economic policies of open markets and globalized capitalism have created social struggles of inequality, poverty, and informality. With predictions that the future rapid urbanization will be concentrated in the Global South, the inability of its cities to contain and govern this spatial concentration, and its social and economic implications, is expected to become more aggravated [9]. Therefore, Global South residents will share an ongoing challenge to survive by whatever means possible. In such conditions, "the companion of scarcity is a complex of creativity, inventiveness and experiment, captured in the notion of the provisional in the relationships and interactions of people in the south of the world" [2, p. 23]. Expanding on the relationships and interactions in parts of the Global South context, the presence of an unfamiliar culture of engagement will be discussed.

\subsubsection{Unfamiliar Culture of Engagement}

The idea of active citizenship is based on citizens' involvement and proactive role in decision-making processes beyond the traditional representational practices of elections. This idea requires cooperation between multiple actors, and the quality of the relationship between state and citizens determines the form and extent of activism. The quality of such relationship is what Connelly $[17$, p. 335] defines as the "culture of engagement". It is "a set of norms and expectations of what kinds of political interactions between state and citizens are appropriate and possible".

In large parts of the Global South, the concept of residents' engagement is unfamiliar to both residents and states. This is related to the socio-political histories of the Global South, which created a void between post-colonial tendencies of state control and new processes working towards liberalization and democratization. On the one hand, the authoritarian regimes which came into power in the post-colonial period created stability, by adopting centralized planning and governance processes based on state-led economic development $[18,19]$. This cultivated a norm of residents' dependency on the state as the sole provider of services, besides a norm of states' controlling and often undermining attitude towards residents' engagement. On the other hand, the more recent introduction of neo-liberal principles focused on economic sectorial development, while largely overlooking the democratic component of change [1,19]. Although local governance, decentralization and public participation are officially encouraged in parts of the Global South, the essential structural arrangements and attitudes required are absent $[16,20]$. In practice, legislative and regulatory foundations often hinder residents' engagement activities.

Official encouragement of civil society and residents' participation occurred as a response to democratization calls. In such state-controlled context, Roy [21] elaborated that civil society is mainly directed towards non-political aspects, limited to providing basic needs and substituting the states' financial and service provision retreat. Consequently, civil society acts as a donor-dependent and emergency relief activity [19] in deprived neighborhoods. 
Additionally, it is strictly regulated, undermined and repressed by the states $[22,23]$. Formal local active groups aiming for the physical improvement of their neighborhood beyond the scope of emergency relief, and outside the informal areas rarely exist. Examples of such groups are found for instance in affluent neighborhoods in Cairo [24]. According to Watson [16] and Bayat [19], this environment creates institutionalized, top-down managed civil society, which is neither coherent nor organized enough to sustain and replicate its achievements. And thus, it is questionable to expect, in such context, that a prominent and leading role is played by civil society in effective resident's participation.

These complex socio-political conditions and histories create an unfamiliar culture of engagement. For example, Malena and colleagues [25, p. 7] described the state-citizen relation in Cambodia as follows: "Due to feelings of inferiority and helplessness, citizens are traditionally quite reluctant to question (let alone confront) authorities and have little expectation that the voice of 'the little man' could have any influence on government actions or decisions". Accordingly, residents are more inclined to either utilize individual options to satisfy their unmet needs, dependent on family ties, or act as NGOs beneficiaries [26]. Meanwhile, the initiation of collective actions and secondary associations for their own problems and neighborhoods is neither a considered alternative nor a familiar culture for residents and officials. Such unfamiliar culture of engagement in the Global South is accompanied by recent but deficient state-supported notions for residents' engagement in neighborhood governance.

\subsubsection{Deficient State-Supported Notions of Residents' Engagement}

In countries such as India, Mexico, Iran and China, some steps have been taken towards fostering the role of residents in neighborhood governance [see 11,27-29]. States have supported the establishment of either local government entities such as residents' committees and neighborhood councils or civil society entities such as neighborhood organizations and homeowners' associations. Although such state support may imply a political will for downscaling governance on the level of neighborhood and for residents' engagement, these grass-roots entities face operational challenges and social consequences.

Operationally, many countries in the Global South have adopted static and centralized formal systems of planning and governance, that are inherited from colonial regimes $[18,30]$. In this regard, a top-down perspective of city planning through large scale master planning and predetermined land use has dominated large parts of the Global South [16]. This is known as the comprehensive/ rational approach to urban planning [31] and does not allow for meaningful residents' participation and engagement. Consequently, this urban planning approach is neither successful in tackling urban challenges in the Global South
[30] nor does it allow for multiple actors' collaboration such as in the postmodern approach of "collaborative" urban planning [32].

The presence of public engagement is not only unsupported operationally in urban planning, but also in urban governance. Studies have pinpointed the dominating influence of local government officials on initiation, management and decision-making in Global South contexts [see 20,27,28]. Vague executive regulations make the initiation and functioning of grass-roots entities vulnerable to officials' interpretations and vary between cities [28]. Additionally, the remnants of the states' tendency to control, and the financial advancement of the private market outplay the power and autonomy of the grass-roots entities in local governance processes. And thus, the role of grass-roots entities is limited in many cases to nothing more than property administration and management. Accordingly, advancing the residents' role in neighborhood-level governance in such contexts can be considered at the "infant level" as described by Zhang and colleagues [20].

Not only do the operational challenges suggest an inadequate downscaling of "enabler, responsive" structural arrangements, but they also affect the agent aspect of residents' willingness and ability to participate. Two social consequences will be highlighted. Firstly, state-supported efforts to involve residents and to promote local active citizenship can be exclusive to specific neighborhoods. For instance, Lombard [11] mentioned that the state promotes local active citizenship in poor urban areas as an aspect of being 'good citizens' in Mexico. In Cairo, the state encourages a form of neighborhood associations in the districts targeted within Greater Cairo future vision to maintain the implemented renovations [33]. These statesupported efforts encourage local active citizenship but are directed towards specific areas and groups. This leads to a public perception of active participation as exclusive in specific areas or by certain sectors to earn their citizenship.

Secondly, the struggles of grass-roots entities and the varying experiences with state-supported channels of residents' engagement can cause an incremental social disadvantage. The social exchange theory [34] is relevant in terms of explaining the circular relationship between local government performance, residents' attitude towards local government, and levels of residents' participation. The continuous struggles faced by residents to participate in local governance under the dominance of the state create a negative connotation concerning the efficiency of grassroots entities. The struggles related to state-supported approaches towards public involvement have been broadly discussed in the literature [see 35,36]. Connelly [37] concluded that such approaches could be beneficial as a starting point. However, their results have a strong impact on residents' evaluation of local participation. This is particularly challenging in the Global South as public involvement norms are based on fruitless experiences. In 
this way, the continuous deficiencies in the state-supported notions of residents' engagement serve to stabilize a hostile attitude towards local activism.

From the above discussion, the socio-political trajectories of the Global South reveal a cycle of unfamiliar culture of engagement and deficient state-supported channels for residents' engagement. They create a problematic context for the development of local active citizenship. A context shaped by "counter-production" due to "actions from public institutions that discourage or hamper steps towards co-production" [38, p. 2]. Therefore, formal entities of activism in neighborhood governance cannot be presumed to exist efficiently in this context. Alternatively, unorganized, spontaneous and social media based groups exist in the Global South [23]. They are active residents' groups functioning beyond the official channels of residents' engagement by creating parallel channels to improve their neighborhoods. It is to this form of active citizenship that we now turn.

\subsection{Distinctive Manifestations of Active Citizenship in Neighborhood Governance}

Cornwall and colleagues [39], and Miraftab [40] emphasized the fact that effective participation from citizens expands beyond the occupation of the spaces of community engagement as offered by governments. Instead, citizens create their local active actions and groups. Studying these local actions and groups falls within attempts to understand "citizenship through performance" [13] by exploring informal bottom-up tactics where citizens actively practice citizenship, and that do not fall under official plans and policies to promote citizenship. Viewed from this perspective, a momentum of activism at the neighborhood level can be observed in the Global South. However, most of the literature on local activism from the Global South contexts focuses on struggling neighborhoods. Examples of such struggling areas are the anti-eviction groups in Sao Paulo [41] and Cape town [42], the grass-roots activities of the poor in the Middle East [43], and even the self-developed spatial plans of the Palestinian Bedouins [44]. Being located in neighborhoods with such peculiar social, political, economic and legal conditions shape the explanation and justification of these local activism practices. Consequently, the literature on local activism in Global South is significantly influenced by the special circumstances of such struggling areas.

Having said that, we claim that the residents of the formal neighborhoods in parts of the Global South are also influenced by the socio-political contexts there and thus, develop distinctive forms of neighborhood activism. Based on a literature review, this section will discuss examples of such active groups in formal neighborhoods from cities in South Africa, and Egypt, and deduce distinctive characteristics from them. These examples reveal unregulated and unregistered residents' initiatives, coalitions, unions and social media groups who actively improve their neighborhoods. They show need-based, reluctant to formalization, and un-confrontational manifestation of local active citizenship.

\subsubsection{Need-Based Collective Actions}

In the following cases, residents undertake informal tactics due to pressing needs for responding to urban problems in their neighborhood. In Cairo, the initiation of grass-roots groups is triggered by the deterioration in the neighborhoods' built environment [45], and the failure of local authorities to address it [46]. The need for improving the built environment and the quality of life are stated as objectives by such groups on social media [see for example $47,48]$. Their activities vary from online campaigns to onthe-ground actions such as neighborhood cleaning up, reporting problems to the municipality, planting trees and gardens, etc. Another radical example was observed in neighborhoods in Johannesburg [see 12,49]. Because of the need to secure their neighborhoods, the residents have organized themselves into unregistered associations and applied spatial security measures consisting of gates, curfew hours and private security guards. Their activities have expanded to include regular meetings to discuss other urban challenges such as neighborhood cleanliness, road maintenance, and even flood control.

A shared characteristic of these examples is that residents are triggered by the failure of local governance to either provide a desired quality of life or to maintain it. This is in line with the two tentative driving forces motivating residents for co-production in poor countries that are defined by Joshi and Moore [26, p. 41] as "decline in governance capacity" and/or "natural logistical barrier". Consequently, the residents are mobilized from a needbased perspective to initiate their collective groups.

\subsubsection{Reluctant to Formalization}

Another character in many of these local groups is being reluctant to formalization. This involves formalization in terms of attaching a legal status to the groups to provide official recognition, to legitimize their activities and to facilitate their collaboration with other actors. In 2003, the local authorities in Johannesburg required the formalization of all neighborhood enclosures by residents. However, due to complicated procedures and high applications costs, most of the residents were reluctant to apply and are continuing illegally [49]. In Cairo, the founders of Heliopolis Heritage initiative still differentiate between their unregistered grass-roots initiative for community mobilization and their new formal foundation [50]. Additionally, the New Nozha coalition founders capitalize on the large number of unofficial followers and supporters in its social media group when addressing local officials as a de facto mean to legitimize the coalition [51].

Reluctance towards formalization may occur when the residents are not aware of the presence of a formal scheme 
for their activities. For instance, in Egypt, it is possible to establish unions on the scale of multiple buildings [52], but the residents are often unaware of this. Another reason for such reluctance was discussed by Bovaird [53], and Bayat [19] who highlighted the discouragement of citizens and their loss of interest when their collective actions became formally organized. This is particularly valid in Global South contexts where complicated procedures exist beside an unfamiliar culture of engagement.

The lack of official recognition may put these groups in a vulnerable position and limit their activity. In South Africa, the informal enclosures were tolerated by local officials in some districts, while other officials banned them because of technical issues or urban management challenges. Additionally, these informal enclosures were discouraged by political parties and researchers. They expressed concerns about the contribution of these informal measures towards widening existing social exclusion, community fragmentation and the privatization of security quality [54]. Although this vulnerability, having a formal status does not seem to be a compelling option to these local active groups. In this respect, the residents are unable to cope with the complicated formal state-citizen relationship. Accordingly, local active groups are reluctant to formalization, and dependent on the lack of surveillance in "soft states" [19], where informality becomes a product of inappropriate formal processes $[21,55]$.

\subsubsection{Un-confrontational Survival Efforts}

The active groups mentioned previously capitalize not only on their informal tactics but also seize possible opportunities to cooperate with local officials through formal channels of participation. Informally, the active members of Heliopolis initiative in Cairo negotiate with shop owners in the neighborhood and encourage them to follow the facade designs codes [56]. Additionally, they raise funds from businesses owners to decorate the neighborhood's main square [57]. On another track, they cooperated with two formal groups from other neighborhoods to lobby for the issuing of an edict to temporarily stop building permits in their neighborhoods [58]. Mitlin and Bartlett [59] mention that residents consider coproduction instead of self-help actions in cases of wide-scale interventions requiring the support of local authorities. This combination of formal and informal methods is applied in un-confrontational manner. The neighborhood enclosures in South Africa were set up by the residents rather than confronting the local government's failure and demanding its rectification. It is a tendency that residents face their neighborhood challenges collectively but quietly, without getting drawn into face-to-face confrontations with the authorities.

These observed efforts seem to follow Watson's [16] description of everyday life in the Global South as "survival efforts", in which citizens negotiate their way through everyday challenges in the cities using their perception of survival and depending on existing networks. It is an un-confrontational coping approach towards improving neighborhoods by seizing on possible tactics and strategies.

\subsubsection{Discussion}

The above section is aimed at uncovering a distinctive manifestation of active citizenship in formal neighborhoods in parts of the Global South by analyzing examples of informal residents' groups in large cities. They actively attempt to improve their neighborhoods, driven by socio-political trajectories in the Global South. Whether these informal groups are represented on social media or are on-the-ground, and whether they are encouraged or criticized, they are part of active citizenship in neighborhood governance in the Global South. In this subsection, we discuss the analyzed groups by reconnecting them to the literature on local activism in the Global South, with reference to two important concepts: quiet encroachment and insurgent citizenship.

Firstly, "quiet encroachment" activism by Bayat [19] introduces an unobtrusive, un-confrontational form of activism. This takes place through individual direct actions by poor and marginalized groups to satisfy their basic needs, particularly in the growing informal/slum areas in the Global South. These individual actions may have an incremental effect on public welfare. Secondly, "insurgent citizenship" was introduced by Holston [60] regarding activism in the peripheral neighborhoods in Brazil and was later discussed by other scholars in different Global South contexts [see 9,18]. It concerns collective, right-based oppositional activities by poor and marginalized selforganized groups. They build on the "right to the city" concept [61] to justify their invasion of or occupation of housing, land, and infrastructure. Here, clashing with the authorities is a part of the process of achieving the goals. "Invented" spaces of citizenship which "confront the authorities" and challenge "the status quo in the hope of larger societal change and resistance to the dominant power relations" [40, p. 1] are integral to its practice. Insurgent citizenship activities were spatialized predominantly in struggling areas by squatters and anti-eviction groups.

The groups analyzed in this paper share characteristics with these concepts but also differ in others. For instance, they share the un-confrontational characteristic found in "quiet encroachment". However, they are collective ones relying on the numbers of supporters- and aiming for the public good of their neighborhood. Additionally, the analyzed groups are collective and self-organized as the insurgent ones, but they are not invasive. They would tend to avoid clashes (protests, sit-ins or violence) as a tactical coping mechanism. Moreover, Holston [60] elaborated on a shift in the awareness of the insurgent groups from advocating their demands as "needs" to "rights" with legal terms and lawsuits. This shift cannot yet describe the analyzed groups. 
Finally, the informal groups analyzed in this paper take place in formal neighborhoods. Thus, they are not falling under the documented practices in "quiet encroachment" and "insurgent citizenship" concepts linking informal active groups with poor neighborhoods, slums, and struggling areas. Although both concepts held notions of (in)formality, (un)confrontation and right-based activism, they are discussed and justified by the poor and marginalized status of the individuals practicing it in slum areas. Meanwhile, the analyzed groups cannot be associated with such status and justifications. They are active residents who although living in formal -legally secured- ordinary neighborhoods, decide to informally and un-confrontationally intervene in their neighborhood. It is a complex reality of interwoven formal strategies and informal tactics taking place by active residents in neighborhood governance in parts of the Global South.

\section{Active Citizenship and Neighborhood Governance: A Literature Dominated by the North- Western Context}

"Active Citizenship" and "Neighborhood Governance" are two terms of interest in policy and academic research, especially in urban neighborhood renewal. However, most of the English language literature and academic research on the active role of the residents in their neighborhoods has been developed in the North-west as most of the urban studies (see section 1). This section aims to highlight the characteristics of the predominant perspectives and experiences concerning local active citizenship, based on the literature, which primarily originates from the Global North. But first, these predominant experiences will be positioned with respect to the shared economic and political forces, besides a widened perspective of citizenship in the North-western context.

\subsection{The North-Western Context}

\subsubsection{Economic and Political Forces}

The North-western context has combined political and economic forces in the past decades, paving the way for citizen engagement in local governance. Economically, the global economic crisis, a neo-liberal approach and welfare state retrenchment contributed significantly to the existence of multi-actor engagement in local governance. These economic drivers limit state-central expenditures and redirect the role of the states towards allowing for the conditions of service provision rather than its direct provision [see 62,63]. Accordingly, North-western cities adopted decentralization and local governance -including neighborhood level- approaches [38,53]. This approach motivates the local governments to diversify their resources by cooperating with private developers and community associations. In other cases, the community mobilized and pushed for this shift in local governance to counteract the consequences of the austerity measures and the failure of local government in supplying for their neighborhoods [64]. To respond to these top-down and bottom-up mobilization efforts, the fixed power and hierarchical organization of local governments shift continuously into more hybridized forms spread among different actors [35]. Consequently, economic forces in the North-western context now allow for more opportunities for residents' effective participation at the neighborhood level.

On a political level, discussions about residents' effective participation attracted considerable interest as a manifestation of modern democratic practices. In the North-western context -defined as developed democratic countries-actors became aware of the democratic deficits jeopardizing the legitimacy of traditional representative practices $[65,66]$. Accordingly, the view on democratic practices extended in the North-western context to "citizens' involvement in decision making or their participation in the decision-making processes outside the main elected local government institutions" [67, p. 4]. This view allows for an increased role for residents at local levels of governance in the form of the civil society [39]. Thus, the culture of engagement in the North-western context is developing in close alignment with the evolution of democratic participation besides, the economic forces towards engaging citizens in public and local affairs there.

\subsubsection{Widened Perspective on Citizenship and Its Neighborhood-Level Spatialization}

Amid the forces of the North-western context, effective participation in local governance has become a part of a widened perspective on defining citizenship and its manifestation. The differentiation between "active" and "passive" characters appeared in how citizenship is redefined amongst politicians and academic researchers [68]. In this regard, citizenship has redefined as "active exercise of responsibilities, including economic selfreliance and political participation. Implicit in this redefinition is a dismantling of the ostensibly "passive" citizenship associated with the post-war, so called "statist" period" [69, p. 94]. Building on this, effective engagement and participation became a right that goes together with the basic political, economic and social rights of the citizen. Not only does this redefinition responsibilizes states to enable and support citizens' active participation as a right, but also motivates the citizens to be demanding for it [36].

The linkage between "citizenship" as being "active" and "effective" in participation spatializes active citizenship philosophy in local urban governance levels. Kearns [70] highlighted the geographical dimension to operationalize active citizenship in local governance. A particular focus was directed at the neighborhood level as the most intimate urban scale to which residents relate, are aware of and are 
significantly influenced by its condition [see 71-73]. In this regard, local active citizenship as a philosophy encompasses the right of effective citizen participation, while as a manifestation it is spatialized in local levels as neighborhoods. To operationalize this, "neighborhood governance" as a form of small-scale governance appeared as a concept linked to participation and responsiveness [74].

The dominant perspective of neighborhood governance is "a set of arrangements for collective decision making and/or public service delivery at the sub-local level" [73, $p$. 343]. Neighborhood governance is a direct interpretation of decentralization -widely promoted in the North-western context- and provides an arena to strengthen the statecitizen relationship [75]. Moreover, it entails a crucial role of active residents either individually or collectively in the process of local governance [65]. This role is also viewed as an opportunity for the community to shift from the continuous failure of central governments to local, communicative, trusted and reliable processes of urban governance.

As described, the dominant perspective on local activism reflects the existing foundations of an active culture of engagement in the North-western context: a culture that is shaped by a combination of its socio-political forces. It is based on a momentum for appropriating various possibilities of state-citizen interaction and a widened perspective on citizenship. These opportunities do not only depend on state support and responsiveness. But they also rely on the civic agency of residents and their capacities to be "willing, able, and equipped" to practice activism [76]. The resultant active culture of engagement in the Northwestern context is a synergy of efforts towards participation, citizenship and accountability by different actors (state and citizens) [77]. It establishes an active cycle in which a responsive state will encourage civic culture and simultaneously a vibrant civic culture will demand and mobilize attentive states [78]. Consequently, in such contexts, the existence of formal grass-roots entities is a significant alternative for residents and officials in governance, and it characterizes the dominant manifestation of local activism.

\subsection{Characteristics of the Dominant Manifestations of Active Citizenship in Neighborhood Governance}

This part highlights the characteristics of the dominant manifestations of local active citizenship and their strong reflection of influences of the North-western context. These manifestations are state-supported, formally recognized and right-based.

\subsubsection{State-Supported Local Activism}

The importance of state role in supporting active citizenship in neighborhood governance has taken place in the literature. This role revolves around enhancing the relationship between state and residents [72] that requires structural and attitudinal changes [79]. These structural and attitudinal changes expand the role of the state in strengthening the sense of local activism. According to Marinetto [65], the role of the state is not only about offering effective spaces of citizen engagement but also to encourage and to incubate the initiatives of active residents. Here, the provision of appropriate spaces of engagement is not a guarantee for collective governance as long as the residents are not empowered and willing to use these spaces by initiating active residents' groups $[63,66]$. For that matter, the institutional arrangements extend the state role to be "educational, learning and awareness raising activities which help people to develop the knowledge, skills and confidence to engage with local decision making" [10, p. 490].

Building on this extended role, the dominant literature has reflected on local activism experiences supported by strategies and policies developed by North-western states to allow for effective participation. Policies have been developed, such as "Participatory society" [80] and "Do-ityourself democracy" [38] in the Netherlands, "Big Society" [81] and "Localism" in the UK [82], and the "Localist" and "Asset-based community development $\mathrm{ABCD}$ " in the US [83].

Additionally, the North-western states have supported the flourishing of local active citizenship by developing funds and capacity building programs on the neighborhood scale. There has been a special focus on state-supported experiences of neighborhood community organization in countries such as; the US [75,84] and countries in the EU [for example 37,38,85]. Even examples showcasing selforganized communities as "sole deliverer and planner" by Bovaird [53] were supported and funded by the government [86]. Consequently, most experiences of local activism in neighborhood governance have been significantly reliant on the presence of state support.

\subsubsection{Formally Recognized Local Activism}

The active residents' groups involved in the dominant neighborhood governance experiences are mostly formally recognized. This is because the perspective of community engagement in neighborhood governance is the "involvement of citizens in the formal structures and processes of governance at neighborhood level, encompassing both strategic and service planning and the detail of service delivery at neighborhood level, while recognizing that citizens' involvement in other collective activities, such as sports or community service, may lead to attempts to influence public policy" [66, p. 2227]. This perspective differentiates the collective activities groups from local activism in neighborhood governance. The collective activities groups are citizen-citizen based, possibly existing informally and focusing on social activities such as playgroups and food cooperatives [53,79]. Meanwhile, local activism in neighborhood governance focuses on an interaction model between the state and 
formal active initiative for increased interdependency with local governance processes [62].

By realizing this perspective, most of the active residents choose from the formally recognized channels of activism to establish their bottom-up initiatives in neighborhood governance. Teernstra and Pinkster [80, p. 58] explained that "resident contestations have been 'channeled' into formal participation arrangements in local decisionmaking”. This appears in the various officially recognized forms of how residents actively organize themselves in the North-western context including neighborhood associations, community enterprises (CEs) and community development corporations (CDCs), etc.

\subsubsection{Right-Based Local Activism}

Local activism in neighborhood governance has a rightbased characteristic in its manifestation. It is a Northwestern perspective of activism as being a key component in modern democracy practices and a citizenship right. Not only this perspective dictates the previously discussed state-support of local activism in neighborhood governance, but also it necessitates that residents demand local activism as a right in practice and that academic researchers improve upon it. Concerning residents, a wide spectrum of formal local activism groups clamors to be heard and to demand accountability from local councils in the form of neighborhood associations. Such associations showcase a civic culture of residents who understand to a significant extent the "active" component in citizenship and demand it through effective participation [77]. On academic research level, studies have taken place to help assess, define and to face the challenges hindering the predominant local activism experiences in the North-western context [see for example $35,87,88]$. These studies have extensively analyzed existing local activism experiences in terms of actors' perceptions and motives, capacity and mobilization, top-down dependency and power frictions. Additionally, strategies of inclusion, solidarity, and stability for effective citizenship in neighborhood governance have been recommended [71]. In conclusion, the predominant experiences of local activism reflect a right based characteristic to the existence of local activism. This is expressed as a well-earned right by the residents besides an expected responsive and enabling attitude from the state and academia.

To summarize, the most prevalent perspectives and experiences in the literature reflect state-supported, formally institutionalized and right-based characteristics and explanations of active citizenship in neighborhood governance. They take the North-western reality as their starting point: a context of democratic participation models, decentralized urban governance and activism as a right. This context has cemented the existence of an active culture of engagement in its societies. Consequently, a dynamic between state-supported spaces of citizen engagement, academic research to optimize these spaces, and vibrant civic culture of formal resident groups claiming their rights characterize the local activism experiences predominantly.

\section{Confronting the Dominant Perspective with the Global South Reality}

This section will confront the North-western leading literature on active citizenship in neighborhood governance with the Global South reality. It will discuss the common and the disparate dimensions of centrality in local activism in both contexts as a reflection on the characteristics highlighted previously.

\subsection{The Common Centrality of "Context " in Shaping Local Activism in Both Worlds}

The importance of "context" in shaping the role of the residents in their neighborhoods is highlighted in many areas of the literature on local active citizenship. However, often the influence of context is discussed while analyzing different neighborhoods within the same city or country, or when comparing similar neighborhood-based initiatives in different but mostly North-west countries [for example 83]. These studies pertain to the influence of the physical condition of the neighborhood; the composition its population; how external residents perceive the neighborhood [89] and the institutional context [88] on defining the active role of the residents. Such contextual influences can: enhance or disable civic activity (at agent and structure levels) [36]; determine the nature of the residents' activity and the reaction of state institutions [75]. Here, we upscale the centrality of regional "context" as a crucial dimension when approaching the subject of local activism in different parts of the World. Bucek and Smith [67], and Watson [16] highlighted the centrality of regional context when comparing the application of participatory planning and local governance approaches between the Global North and the Global South. Additionally, it became very apparent recently when comparing, for example, homeowners' associations in the US and China [28].

To reflect on the centrality of the regional context, the previously discussed local active citizenship manifestations were by-products of the existing culture of engagement in each of the Global South and North-western contexts. However, as the culture of engagement is fundamentally different, the local activism practices that develop differ accordingly. This culture of engagement places specific assumptions at the center of how local activism comes into being and is practiced. Since local activism practices in the main literature are a result of an "active" culture of engagement in the North-western countries, the assumption of local activism to be a right-based, formal and statesupported notion strongly prevails. However, Global South countries have tended to exhibit a "hostile" culture of 
engagement. It is erroneous to assume that local activism in such different context would have similar characteristics. The above characteristics may only be relevant to a crosssection of how local activism is practiced and perceived in the Global South. Instead, the examples in section two reveal need-based, reluctant to formality and unconfrontational characteristics in the Global South. In conclusion, the contextual setting is not only influential at a detailed or operational level, but also the theoretical level [39]. It is a common significant centrality on how local activism is manifested, not only among different neighborhoods or cities but also between global regions.

\subsection{The Disparate Dimensions of Centrality in Local Activism between the Two Contexts}

\subsubsection{Need-Based vs. Right-Based}

As shown in section three, the dominant perspective on local activism has relied on viewing the activity of residents in their neighborhood as right-based actions. It is a view that assumes the prevalence of a modern, participatory democratic approach in which the active role of residents is an integral and crucial aspect of basic citizen's right. This view offers the residents a safe net to practice local activism, even when practicing it from a service-oriented rational sometimes. So, although local activism is motivated by the residents' sense of necessity to act according to a problem or need, they can count on a right-based foundation to legitimize their actions through institutionalized bottom-up entities. By contrast, the analyzed examples from Global South suggest a need-based activity. It is a context in which deficient traditional democratic practices prevail, and consequently, local active citizenship is not a familiar part of the regional perception of democracy and citizen's rights. It also encounters the deficiency of local government entities in managing the "housekeeping" of basic services [90] such as security, waste management, maintenance of public spaces, etc. Bucek and Smith [67] mention that the role of the community in substituting for public service provision in poor countries is an inevitable necessity. In this respect, the central role of the right-based dimension in practicing local activism as depicted in the main literature is unlikely to be mirrored in parts of the Global South. A need-based dimension is more likely to be prevalent.

\subsubsection{Selective State-Citizen Collaboration vs. State- Citizen Collaboration}

The strong conviction that state-citizen collaboration is central to the active role of citizens in neighborhood governance should be reconsidered when reflecting on the Global South. Chaskin and Garg [90] highlighted the widely-held belief in a "connected, coordinated and responsive approach" towards service provision and social change in neighborhood governance. The issue here is the assumption that state-citizen collaboration is an embedded thought common to the various actors. This is evident in the "state-supported" and "formally recognized" characteristics described in section three. Such belief allows for the expectation of state support -even if minimal or flawed- of effective citizen engagement and the active residents' willingness to interact with local officials.

The expected state-citizen collaboration focuses on the realm of practicing local active citizenship through "invited" spaces of citizen engagement. These are spaces officially created and/or appropriated to contain bottom-up initiated active citizenship practices [40]. It is the institutionalized model of local active citizenship whose responsibilities are defined and practiced by laws and regulations and is manifested by formal grass-roots entities. Cornwall and colleagues [39] describe this model as the citizens' active acceptance of a state-provided invitation to spaces of participation and engagement. These "invited" spaces rely on state-citizen collaboration and represent the dominant examples of local activism in the literature. The "invited" spaces assume a choice between diverse legitimate and recognized alternatives of activism whereby local active groups can choose from and organize themselves accordingly. But since this central belief is related to the North-western context of an "active" culture of engagement, what if the context is of an "unfamiliar" culture of engagement? To what extent do the "invited" spaces represent local activism in such a context? Thus, to what extent is state-citizen collaboration central to the practice of local activism in the Global South?

As shown in the Global South, there seems to be a case of "counter-production" actions from the state. These counteractions make the "invited" spaces of local active citizenship appear to be alone an unsatisfactory alternative [29]. According to Miraftab [18], the "invited" spaces in the Global South are occupied by formally-recognized grass-roots organizations to deal with the systems of hardship. Based on this, the examples previously mentioned in parts of the Global South reflect that the active residents' groups deal with these "invited" spaces selectively. In these examples, the active residents' groups can at times be interested in seizing the "invited" spaces of activism by being connected to the local officials and becoming formal. But also, they can decide to be disconnected by being unregulated and to solve the neighborhood's challenges themselves. It is an unconfrontational coping mechanism with the systems of hardship that acknowledges the collaboration with the state while tactically overlooking it at other moments. Accordingly, the role of "invited" spaces in representing the active role of the residents in the formal neighborhoods in the Global South can be limited.

This limited representation entails that state-citizen collaboration is not a central aspect in the global South. Although lacking accurate statistics, it is clear that unregistered local active residents' groups in the formal neighborhoods do exist. Van Houwelingen [91] presented a study in Japan focusing on a wide selection of 
neighborhood associations in different cities, mostly with no legal status and no connection to local officials. Also, it recognizes the importance of studying such unregistered collective local activities as they offer a realistic representation of the active role of the Japanese in their neighborhoods. This argument can have important relevance to the Global South context of hardship. To cope with this context, active residents interchange between connecting and disconnecting from the state while intervening in their neighborhood. This differs from the prevalent belief in state-citizen collaboration as the main path for practicing effective local activism. Selective statecitizen collaboration might be more central to the reality of Global South local activism.

\section{Conclusions and Discussion}

This paper focused on understanding "citizenship through performance" [13] within the context of neighborhood governance in parts of the Global South context. The subject of local activism in the Global South has been recognized and tackled in recent studies. However, these studies have focused mainly on resistive practices in peripheral and informal areas as undertaken by marginalized and oppressed citizens. Here, we shed light on examples of local active citizenship tactics inside formal neighborhoods in cities of the Global South.

The formal neighborhoods in the Global South may not be facing the severe lack of basic services and the tenure ship struggles experienced in the informal areas, however, they are still suffering from urban deterioration and incompetent local government. On the one hand, active residents have a legal stake in their neighborhoods, aware that the local government is at least responsible for maintaining the quality of the neighborhood. On the other hand, they are bound by a context where local activism is unclear to officials and residents, and state-citizen collaboration is not a norm. This complexity produces active residents" groups who use the "invited" spaces of citizen engagement but also create parallel spaces for local activism as coping mechanisms. To make sense of how these active groups are positioned in the literature of "active citizenship" in the context of "neighborhood governance", they were found to be dissimilar to the conventions and experiences of the main North-western literature. Based on the crucial centrality of "context", the North-western literature is invaluable in guiding and contributing to the improvement of local active citizenship practices in contexts where the centrality of right-based and state-citizen collaboration considerations are recognized. However, in parts of the Global South context where local activism is central to need-based considerations and statecitizen collaboration is selective, the main North-western literature can be very limited in helping to understand local activism.
Having said that, the issue in this paper is not about the importance of the North-western perspective and experiences. It is about the extent of their ability to explain what happens in other cities and enrich the body of knowledge accordingly. At the core of this paper, we neither aim at generalizing the contextual influences nor specifying the resultant distinctive local activism to the Global South. It is a wider debate among scholars but which in many cases acknowledges the diversity within the Global South and the need for a multi-central production of knowledge [6]. Accordingly, the ideas in this paper should be perceived within a frame acknowledging the diversity and peculiarity of the urban setting in different countries. And thus, we aimed at shedding light on a form of distinction in local activism in parts of the Global South. By returning to Mabin's question about what specific ideas and relationships in the South that differ from the ones formed in the 'west' or 'north' [2], we suggested two dimensions; right-based vs. need based and state-citizen collaboration vs. selective state-citizen collaboration. Also, the paper pinpointed the distinctive characteristics of neighborhood activism in parts of the Global South that shaped this variation. This theoretical perspective does not only emphasize the need to improve our understanding on how local communities organize themselves in formal neighborhoods in Global South contexts, but it also informs scholars with possible starting points for further empirical research.

Moving forward in balancing between specificity and generalization in which the context and where the theory is produced matter [3,5], it is crucial to understand the informal tactics created by residents to satisfy their unmet needs in an un-confrontational coping manner. Their defacto presence affects the neighborhoods and may have a potential incremental effect on how local officials and residents perceive the role of residents in their neighborhoods and, by extension, their influence on neighborhood governance. Accordingly, in-depth investigation of how these practices function regarding the suggested characteristics (need-based, reluctance to formalization and un-confrontational) is crucial. Cornwall [92] stressed the need not only to focus on optimizing invited spaces and to redirect the residents to them but also to investigate and understand the "instances of participation" created by the residents with their own "terms of engagement". Only by achieving this better understanding, scholars can suggest how communities in contexts of the Global South can move forward regarding effective activism in neighborhood governance.

\section{Acknowledgements}

The research leading to this review is sponsored by a $\mathrm{PhD}$ scholarship from the Egyptian Ministry of Higher Education under the name of "Missions call for 2015-2016". 


\section{REFERENCES}

[1] O. Yiftachel, "Essay: Re-engaging Planning Theory? Towards 'South-Eastern' Perspectives," Plan. Theory, vol. 5, no. 3, pp. 211-222, Nov. 2006.

[2] A. Mabin, "Grounding southern city theory in time and place," in The Routledge Handbook on Cities of the Global South, S. Parnell and S. Oldfield, Eds. 2014, pp. 21-36.

[3] A. Roy, "The 21st-Century Metropolis: New Geographies of Theory,” Reg. Stud., vol. 43, no. 6, pp. 819-830, Jul. 2009.

[4] J. Comaroff and J. L. Comaroff, "Theory from the South: Or, how Euro-America is Evolving Toward Africa," Anthropol. Forum, vol. 22, no. 2, pp. 113-131, Jul. 2012.

[5] S. Parnell and S. Oldfield, Eds., HANDBOOK ON CITIES OF THE GLOBAL SOUTH. 2014.

[6] R. W. Connell, "Social science on a world scale," in Southern Theory: Social Science and The Global Dynamics of Knowledge, A\&U Academic, 2007, pp. 211-232.

[7] Armelle Choplin, translated by Oliver Waine, "DeWesternising Urban Theory", Metropolitics, 5 December 2012.

[8] J. Robinson, "New geographies of theorizing the urban: Putting comparison to work for global urban studies," in The Routledge Handbook on Cities of the Global South, S. Parnell and S. Oldfield, Eds. 2014, pp. 57-70.

[9] V. Watson, "Planning and the 'stubborn realities' of global south-east cities: Some emerging ideas," Plan. Theory, vol. 12, no. 1, pp. 81-100, 2012.

[10] R. Andrews, R. Cowell, J. Downe, S. Martin, and D. Turner, "Supporting Effective Citizenship in Local Government: Engaging, Educating and Empowering Local Citizens," Local Gov. Stud., vol. 34, no. 4, pp. 489-507, Aug. 2008.

[11] M. Lombard, "Citizen Participation in Urban Governance in the Context of Democratization: Evidence from LowIncome Neighbourhoods in Mexico," Int. J. Urban Reg. Res., vol. 37, no. 1, pp. 135-150, 2013.

[12] K. Landman and S. Liebermann, "PLANNING AGAINST CRIME: Preventing crime with people not barriers," SA CRIME Q., no. 11, pp. 21-26, 2005.

[13] N. Verloo, "Learning from informality? Rethinking the mismatch between formal policy strategies and informal tactics of citizenship," Curr. Sociol., vol. 65, no. 2, pp. 167 181, Mar. 2017.

[14] S. Patel, "Is there a 'south' perspective to urban studies?" in The Routledge Handbook on Cities of the Global South, S. Parnell and S. Oldfield, Eds. 2014, pp. 37-47.

[15] J. Robinson, "Starting from anywhere, making connections: globalizing urban theory,” Eurasian Geogr. Econ., vol. 57, no. 4-5, pp. 643-657, 2016.

[16] V. Watson, "Seeing from the South: Refocusing Urban Planning on the Globe's Central Urban Issues," Urban Stud., vol. 46, no. 11, pp. 2259-2275, Oct. 2009.
[17] S. Connelly, "Participation in a Hostile State: How do Planners Act to Shape Public Engagement in Politically Difficult Environments?" Plan. Pract. Res., vol. 25, no. 3, pp. 333-351, Jun. 2010.

[18] F. Miraftab, "INSURGENT PLANNING: SITUATING RADICAL PLANNING IN THE GLOBAL SOUTH," Plan. Theory, vol. 8, no. 1, pp. 32-50, 2009.

[19] A. Bayat, Life as politics: how ordinary people change the Middle East. Stanford University Press, 2013.

[20] Q. Zhang, E. H. K. Yung, and E. H. W. Chan, "Towards Sustainable Neighborhoods: Challenges and Opportunities for Neighborhood Planning in Transitional Urban China," Sustainability, vol. 10, no. 2, p. 406, Feb. 2018.

[21] A. Roy, "Urban Informality: Toward an Epistemology of Planning," J. Am. Plan. Assoc., vol. 71, no. 2, pp. 147-158, 2005.

[22] S. Connelly, "Deliberation in the face of power: Stakeholder planning in Egypt," Policy Soc., vol. 28, no. 3, pp. 185-195, Oct. 2009.

[23] P. Kamruzzaman, "Introduction - civil society in the global South," in Civil Society in the Global South, no. October, 2018, pp. 1-24.

[24] S. Ben Néfissa, "Cairo's City Government: The Crisis of Local Administration and the Refusal of Urban Citizenship," in Cairo Contested: Governance, Urban Space, and Global Modernity, D. Singerman, Ed. American University in Cairo Press, 2009, pp. 177-198.

[25] C. Malena et al., "LINKING CITIZENS AND THE STATE: AN ASSESSMENT OF CIVIL SOCIETY CONTRIBUTIONS TO GOOD GOVERNANCE IN CAMBODIA," 2009.

[26] A. Joshi and M. Moore, "Institutionalised Co-production: Unorthodox Public Service Delivery in Challenging Environments," J. Dev. Stud., vol. 40, no. 4, pp. 31-49, Apr. 2004.

[27] M. Momeni, H. Shamskooshki, and M. Javadian, "Application of neighborhoods council associations in sustainable urban management based on citizen participation," in Procedia Engineering, 2011, vol. 21, pp. 65-71.

[28] S. He, "Homeowner associations and neighborhood governance in Guangzhou, China," Eurasian Geogr. Econ., vol. 56, no. 3, pp. 260-284, May 2015.

[29] G. Williams, B. V Thampi, D. Narayana, S. Nandigama, and D. Bhattacharyya, "Performing Participatory Citizenship Politics and Power in Kerala's Kudumbashree Programme," J. Dev. Stud., vol. 47, no. 8, pp. 1261-1280, Aug. 2011.

[30] UN-Habitat, "Planning sustainable cities: Global Report on Human Settlements," London- UK, 2009.

[31] J. Friedmann, "The Future of Comprehensive Urban Planning: A Critique," Public Adm. Rev., vol. 31, no. 3, pp. 315-326, 1971.

[32] P. Healey, Collaborative planning: Shaping places in fragmented societies, vol. 14, no. 2. MACMILLAN PRESS LTD, 1997.

[33] S. Alkhalafawy, “ محافظ القاهرة: شارع الألفى أول تجربة 
Cairo Governorate: Alfi Street Is the First Occupants' Union Pilot]," Youm7 News, 17-Jul-2017.

[34] S. H. Mohammadi, S. Norazizan, and N. Ahmad, "Citizens' Attitude toward's Local Government and Citizen's Participation in Local Government," J. Am. Sci., vol. 6, no. 11, pp. 575-583, 2010.

[35] A. WALLACE, "New Neighbourhoods, New Citizens? Challenging 'Community' as a Framework for Social and Moral Regeneration under New Labour in the UK," Int. J. Urban Reg. Res., vol. 34, no. 4, pp. 805-819, Dec. 2010.

[36] J. Murray, B. Tshabangu, and N. Erlank, "Enhancing participatory governance and fostering active citizenship: An overview of local and international best practices," Politikon, vol. 37, no. 1, pp. 45-66, 2010.

[37] S. Connelly, "Looking inside public involvement: How is it made so ineffective and can we change this?" Community Dev. J., vol. 41, no. 1, pp. 13-24, 2006.

[38] R. Kleinhans, "False promises of co-production in neighbourhood regeneration: the case of Dutch community enterprises," Public Manag. Rev., vol. 19, no. 10, pp. 1500 $1518,2017$.

[39] A. Cornwall, S. Robins, and B. Von Lieres, "States of Citizenship: Contexts and Cultures of Public Engagement and Citizen Action,” IDS Work. Pap., no. 363, pp. 01-32, Mar. 2011.

[40] F. Miraftab, "Invited and Invented Spaces of Participation: Neoliberal Citizenship and Feminists' Expanded Notion of Politics," Wagadu, vol. 1, no. Spring, pp. 1-7, 2004.

[41] J. Holston, "Insurgent Citizenship in an Era of Global Urban Peripheries," City Soc., vol. 21, no. 2, pp. 245-267, Dec. 2009.

[42] [F. Miraftab, "Insurgent Planning: Situating Radical Planning in the Global South," Readings Plan. Theory Fourth Ed., no. February 2009, pp. 480-498, 2016.

[43] A. Bayat, "Social Movements, Activism and Social Development in the Middle East," 3, 2000.

[44] A. Meir, "Bedouin, the Israeli state and insurgent planning: Globalization, localization or glocalization?" Cities, vol. 22 , no. 3, pp. 201-215, 2005.

[45] GOPP, “Greater Cairo Urban Development Strategy: Part I: Future Vision and Strategic Directions," Cairo-Egypt, 2012.

[46] D. Sims, Uderstanding Cairo: The logic of a city out of contol. Cairo-Egypt: The American University in Cairo Press, 2012.

[47] Heliopolis Heritage initiative, "مبادرة تراث مصر الجديدة" Heliopolis Heritage Initiative - About," Facebook official page, 2011. [Online]. Available: https://tinyurl.com/y6t4sxkz. [Accessed: 27-Feb-2019].

[48] New Nozha Residents coalition, “ أئتلاف سكان النزهة ـ New Nozha Residents coalition: About,” Facebook official page, 2016. [Online]. Available: https://tinyurl.com/y5v2dkt5. [Accessed: 27-Feb-2019].

[49] C. Bénit-Gbaffou, S. Didier, and M. Morange, "Communities, the Private Sector, and the State," Urban Aff. Rev., vol. 43, no. 5, pp. 691-717, May 2008.
[50] C. Asmar, "Heliopolis heritage initiative efforts, Interview in Monte Carlo Radio Station on 13-08-2016 (Arabic)." Choucri AmsarChannel on Youtube, p. Audio: 5:46-6:09, 2016.

[51] K. A. Kader, "New Nozha Coalition first meeting with local authorities," ائتخلاف سكان النزهة الجديدة "New Nozha residetns coalitions" Facebook Public Page, 2018. [Online]. Available: https://tinyurl.com/yxd7omsb. [Accessed: 12Mar-2019].

[52] MHUUD, " اللائحة التنفيذية لقانون البناء الصادر بالقانون [The Unified Building Law no. 119 for the Year 2008 and the Executive Regulations]". Egypt: Al Wakae'e Almasria's Issue no. 12- released on Wednesday 12th of Rabi'e Alakher, 1430 (8th of April 2009), 2009, pp. 144-145.

[53] T. Bovaird, "Beyond Engagement and Participation: User and Community Coproduction of Public Services," Public Adm. Rev., vol. 67, no. 5, pp. 846-860, Sep. 2007.

[54] K. Landman, "Gated communities in South Africa: Building bridges or barriers," in International Conference on Private Urban Governance, 2002, no. June 2002, pp. 1-10.

[55] L. Porter, "Informality, the Commons and the Paradoxes for Planning: Concepts and Debates for Informality and Planning," Plan. Theory Pract., vol. 12, no. 1, pp. 115-120, 2011.

[56] Heliopolis Heritage initiative, "Advertisement Panels Violations," Post on Facebook official page, 2018. [Online]. Available: https://tinyurl.com/y5majd6u. [Accessed: 13Mar-2019].

[57] M. Bassel, "The Heliopolis Heritage Foundation: Preserving One of Cairo's Historic Gems," Community Times, Cairo, Egypt, 2018.

[58] R. Mahmoud, "حكاوي المعادى Maadi Stories Symposium (Arabic)," Maadi Yacht Club Magazine, pp. 40-44, 2018.

[59] D. Mitlin and S. Bartlett, "Editorial: Co-production-key ideas," 2018.

[60] J. Holston, "Urban Citizens," in Insurgent Citizenship: Disjunctions of Democracy and Modernity in Brazil, Princeton university Press, 2008.

[61] H. Lefebvre, Writing on Cities. Blackwell, 1996.

[62] R. van Dam, M. Duineveld, and R. During, "Delineating Active Citizenship: The Subjectification of Citizens' Initiatives," J. Environ. Policy Plan., vol. 17, no. 2, pp. 163 179, Mar. 2015.

[63] J. Beaumont and W. Nicholls, "Plural Governance, Participation and Democracy in Cities," Int. J. Urban Reg. Res., vol. 32, no. 1, pp. 87-94, Mar. 2008.

[64] D. E. Booher, "Collaborative governance practices and democracy," Natl. Civ. Rev., vol. 93, no. 4, pp. 32-46, 2004.

[65] M. Marinetto, "Who Wants to be an Active Citizen?" Sociology, vol. 37, no. 1, pp. 103-120, Feb. 2003.

[66] I. Docherty, R. Goodlad, and R. Paddison, "Civic Culture, Community and Citizen Participation in Contrasting Neighbourhoods," Urban Stud., vol. 38, no. 12, pp. 22252250, Nov. 2001. 
[67] J. Bucek and B. Smith, "New approaches to local democracy: direct democracy, participation and the 'third sector'," Environ. Plan. C, vol. 18, pp. 3-16, 2000.

[68] A. M. Jaggar, “Arenas of citizenship,” Int. Fem. J. Polit., vol. 7, no. 1 , pp. 3-25, 2005.

[69] V. Schild, "New Subjects of Rights? Women's Movements and the Construction of Citizenship in the 'New Democracies," in Cultures of Politics Politics of Cultures: Re-visioning Latin American Social Movements, S. E. Alvarez, E. Dagnino, and A. Escobar, Eds. Colorado: Westview Press, 1998, pp. 93-117.

[70] A. Kearns, "Active citizenship and local governance: political and geographical dimensions," Polit. Geogr., vol. 14, no. 2, 1995.

[71] V. Cattell, "Having a Laugh and Mucking in Together: Using Social Capital to Explore Dynamics Between Structure and Agency in the Context of Declining and Regenerated Neighbourhoods," Sociology, vol. 38, no. 5, pp. 945-963, Dec. 2004.

[72] M. Farrelly and H. Sullivan, "Discourses of Democracy in Neighborhood Governance," Crit. Policy Stud., vol. 4, no. 3, pp. 234-249, Oct. 2010.

[73] C. Durose and V. Lowndes, "Neighbourhood Governance: Contested Rationales within a Multi-Level Setting - A Study of Manchester," Local Gov. Stud., vol. 36, no. 3, pp. 341-359, Jun. 2010.

[74] V. Lowndes and H. Sullivan, "HOW LOW CAN YOU GO? RATIONALES AND CHALLENGES FOR NEIGHBOURHOOD GOVERNANCE," Public Adm., vol. 86, no. 1, pp. 53-74, Mar. 2008.

[75] R. J. Chaskin and D. M. Greenberg, "Between Public and Private Action," Nonprofit Volunt. Sect. Q., vol. 44, no. 2, pp. 248-267, Apr. 2015.

[76] R. Andrews, R. Cowell, and J. Downe, "Support for active citizenship and public service performance: An empirical analysis of English local authorities," Policy Polit., vol. 36, no. 2, pp. 225-243, 2008.

[77] R. Tandon, "Linking Citizenship, Participation and Accountability: A Perspective from PRIA," IDS Bull., vol. 33, no. 2, pp. i-viii, Apr. 2002.

[78] R. Andrews and D. Turner, "Modelling the Impact of Community Engagement on Local Democracy," Local Econ., vol. 21, no. 4, pp. 378-390, 2006.

[79] J.-M. Baer, "Neighbourhood Governance - Capacity for Social Integration- Neighbourhood Govern," 2007.

[80] A. B. Teernstra and F. M. Pinkster, "Participation in neighbourhood regeneration: achievements of residents in a Dutch disadvantaged neighbourhood," Urban Res. Pract., vol. 9, no. 1, pp. 56-79, Jan. 2016.

[81] T. Bovaird and E. Loeffler, "From Engagement to Coproduction: The Contribution of Users and Communities to Outcomes and Public Value," Volunt. Int. J. Volunt. Nonprofit Organ., vol. 23, no. 4, pp. 1119-1138, Dec. 2012.

[82] N. Bailey, G. Bramley, and A. Hastings, "Symposium Introduction: Local Responses to "Austerity," Local Gov. Stud., vol. 41, no. 4, pp. 1-11, May 2015.
[83] D. Varady, R. Kleinhans, and M. van Ham, "The potential of community entrepreneurship for neighbourhood revitalization in the United Kingdom and the United States," J. Enterprising Communities People Places Glob. Econ., vol. 9, no. 3, pp. 253-276, Aug. 2015.

[84] R. M. Silverman and K. L. Patterson, "Community- and Neighbourhood-Based Organisations in the United States," in International Encyclopedia of Housing and Home, vol. 1, Elsevier, 2012, pp. 186-193.

[85] N. Bradford, "Place Matters and Multi- Level Governance: Perspective on a New Urban Policy Paradigm," Policy Options, vol. 25, no. 2, pp. 39-44, 2004.

[86] L. Trewhale, "Falmouth's notorious Old Hill estate was known as Beirut but is now a community haven," Cornwall Live, 2018. [Online]. Available: https://tinyurl.com/y4958vuz. [Accessed: 14-Mar-2019].

[87] R. Andrews, R. Cowell, and J. Downe, "Promoting civic culture by supporting citizenship: What difference can local government make?" Public Adm., vol. 89, no. 2, pp. 595610, 2011.

[88] M. Scott, D. Redmond, and P. Russell, "European Planning Studies Active Citizenship and Local Representational Politics in Twenty-First Century Ireland: The Role of Residents Groups within Dublin's Planning Arena," 2012.

[89] R. Forrest and A. Kearns, "Social Cohesion, Social Capital and the Neighbourhood," Urban Stud., vol. 38, no. 12, pp. 2125-2143, Nov. 2001.

[90] R. J. Chaskin and S. Garg, "The Issue of Governance in Neighborhood-Based Initiatives," Urban Aff. Rev., vol. 32, no. 5, pp. 631-661, May 1997.

[91] P. van Houwelingen, "Neighborhood Associations and Social Capital in Japan," Urban Aff. Rev., vol. 48, no. 4, pp. 467-497, 2012.

[92] A. Cornwall, "Locating Citizen Participation," IDS Bull., vol. 33, no. 2, pp. i-x, Apr. 2002.a 